\title{
Letture del contemporaneo francese, a cura di Gianfranco Rubino
}

\section{Rosa Galli Pellegrini}

\section{(2) OpenEdition}

1 Journals

\section{Edizione digitale}

URL: http://journals.openedition.org/studifrancesi/35211

DOI: 10.4000/studifrancesi.35211

ISSN: 2421-5856

\section{Editore}

Rosenberg \& Sellier

\section{Edizione cartacea}

Data di pubblicazione: 1 novembre 2005

Paginazione: 452

ISSN: 0039-2944

\section{Notizia bibliografica digitale}

Rosa Galli Pellegrini, «Letture del contemporaneo francese, a cura di Gianfranco Rubino», Studi Francesi [Online], 146 (XLIX | II) | 2005, online dal 30 novembre 2015, consultato il 18 avril 2021. URL: http:// journals.openedition.org/studifrancesi/35211 ; DOI: https://doi.org/10.4000/studifrancesi.35211

Questo documento è stato generato automaticamente il 18 avril 2021.

\section{(c) $($ i) $(9)$}

Studi Francesi è distribuita con Licenza Creative Commons Attribuzione - Non commerciale - Non opere derivate 4.0 Internazionale. 


\title{
Letture del contemporaneo francese, a cura di Gianfranco Rubino
}

\author{
Rosa Galli Pellegrini
}

\section{NOTIZIA}

Letture del contemporaneo francese, a cura di GIANFRANCO RUBINO, Roma, Bulzoni, 2004, pp. 132.

1 Sotto la supervisione di Gianfranco Rubino, direttore del LARC (Laboratorio di Ricerca sul Contemporaneo), un gruppo di giovani studiosi affronta la lettura di alcuni romanzi dell'extrême contemporain. Introdotto da una Premessa del curatore (pp. 9-15), la raccolta si apre con il contributo di GRAZIA TAMBURINI, che legge Miette di Bergounioux (pp. 17-34), mentre PAOLO TOMMASIA propone una rivisitazione di Rimbaud le fils di Michon (pp. 35-51). Nell'ordine, poi, LUCA BEVILACQUA, ELISABETTA SIBILIO, MARINA MINUCCI e ANNIE OLIVIER analizzano L'Enterrement di Bon (pp. 53-66), La Moustache di Carrère (pp. 67-80), Je m'en vais di Echenoz (pp. 81-93), Dans le train di Oster (pp. 95-113). Tutti di buon livello critico, i lavori di questi giovani studiosi danno un utile contributo alla diffusione della conoscenza, in Italia, di questa stagione del romanzo francese contemporaneo. Chiude la serie il lavoro di GIANFRANCO RUBINO su Faire l'amour (pp. 115-130), nel quale lo studioso mette in risalto gli scarti e le attinenze di questo ultimo romanzo di Toussaint con la sua narrativa precedente. 